\title{
Homeostasis Events for Serum Ionized Calcium Accompanied by Anti- Mullerian Hormone in Some Women with Primary Infertility in Babylon Province
}

\author{
Noran Jameel Ibraheem ${ }^{\mathrm{a}} \quad$ Manar Muhammad Hasan Al-Murshidi ${ }^{\mathrm{b}}$ \\ Walaa Saleh Hasan ${ }^{\mathrm{c}}$ \\ ${ }^{a, b}$ Department of biology, college of Science for women, University of Babylon, Al- Hila, Iraq. \\ ${ }^{c}$ Department of biology, college of Science, University of Babylon, Al- Hila, Iraq, \\ noranjameel@gmail.com
}

Submission date:- 2/9/2018 Acceptance date:- 16/9/2018 Publication date:- 29/1/2019

Keywords: ionized calcium homeostasis, women infertility, anti-Mullerian hormone

\begin{abstract}
Ionized calcium has a biological activity, this study has been debated whether the status of calcium homeostasis in correlated with anti-Mullerian hormone level how, does influence on the reproductive ability in some premenopausal women. The current study was conducted in the college of science for women during the period from February 2015 to May 2016, study population was involved eighty volunteer women (20-35) years enrolled in this study, fifty women with primary infertility considered as a study group, while the other 30 volunteers parous women considered as a control group. ELISA kit was used to assay the serum level of anti-Mullerian and parathyroid hormone, whereas colorimetric technique was applied to evalute the total calcium, albumin, and inorganic phosphorus serum level, while ionized calcium is achieved by special equation depending on the total calcium and albumin level. Independent T-test analysis was applied to specify any significant variation for investigated parameters between control and study group, linear regression analyses were used to explore the association between ionized calcium and antiMullerian hormone (AMH) level in both control and infertile groups. The results revealed that infertile group have significantly $(\mathrm{p}<0.001)$ lower mean serum ionized calcium level $(4.31 \pm 0.61 \mathrm{mg} / \mathrm{dl})$ than the control group $(5.57 \pm 0.45 \mathrm{mg} / \mathrm{dl})$ accompanied by significantly $(\mathrm{p}<0.001)$ increase in parathyroid hormone level $(49.2 \pm 32.2$ $\mathrm{ng} / \mathrm{dl})$ in a study group in comparison with a control group whose reported $(92.1 \pm 22.2 \mathrm{ng} / \mathrm{dl})$ mean concentration ,infertile women revealed significantly decrease mean level in anti-Mullerian hormone $(2.59 \pm 1.38 \mathrm{ng} / \mathrm{d})$ compared with the control group $(3.44 \pm 1.00 \mathrm{ng} / \mathrm{dl})$, linear regression analyses revealed a significant positive relation between's ionized calcium concentration and AMH level $(\mathrm{r}=0.58, \mathrm{p}=0.000, \mathrm{n}=40)$ in the control group, as well, there was a significant strong positive connection was seen between serum ionized calcium and AMH level for the infertile group ( $\mathrm{r}=0.70$, $\mathrm{p}=0.000, \mathrm{n}=50$ ), our conclusion suggested that any physiological process including reproductive ability may need in one way or another to balance in the availability of ionized calcium.
\end{abstract}




\section{1-Introduction}

A significant number of specialists supported vitamin D involvement in reproductive potential, however, few examinations have explored the capability of calcium homeostasis on ovarian reserve and reproductive ability in human. The idea of our study arising from animal trial suggestion about calcium supplementation was provided to vitamin D receptor (VDR)mice, whereas this treatment ameliorated infertility though vitamin D is absent [1], as well that vitamin $\mathrm{D}$ deficiency can be to compensate by supplementation with adequate calcium and phosphorous as indicated by another investigator [2]. As calcium flow have been appeared to be essential in directing an expansive range of the physiological process, even slight height or regression of calcium particle in the extracellular liquid frequently causes excess rapid physiological effects $[3,4]$

The serum or plasma calcium is available in three structures: around 40 percent of the calcium is joined with proteins, around 10 percent of calcium joined with different substances (phosphate and citrate, for instance) the ionized form of calcium composed about 50 percent, this ionic calcium is physiologically dynamic form and vital for most task of calcium in the body [5],though nearly half the calcium in the serum is combined with protein specifically albumin, but any change in protein concentration does not influence on ionized calcium portion while cause changes in total calcium concentration [6].

The role of calcium ion as fundamental messenger within the cells tissues of the body, indeed ionized $\mathrm{Ca}$ is the most widely recognized as a transduction signal in biology owing to its capacity in binding reversibility to proteins and combine with anions, citrate and bicarbonate, for instance [7], in that manner many studies were conducted to investigate the task of current calcium ion the physiology of oocyte in numerous species of animals and have setup the part of calcium in oocyte activation and contributed in follicular development so confirmed that increases in an intracellular free $\mathrm{Ca}^{+2}$ in mouse oocytes is fundamental for automatically meiotic resumption [8,9], alongside calcium the inorganic phosphorous (iP) which other biochemical agents have strict control of plasma calcium and approximately all of the phosphorous found in the extracellular liquid area as inorganic phosphate form, the physiological level of inorganic phosphorus is an essential for ordinary cell work [ 10,11], this biochemical agent and calcium ion must be adjusted by endocrine and metabolic agents including vitamin $\mathrm{D}$ and parathyroid hormone particularly when an excess of parathyroid hormone (PTH) level the kidney would response by raises the reabsorption of renal calcium and phosphate disposal $[12,13]$. Accordingly, this study has been debated to assess whether the ionized calcium homeostasis have possible effect on ovarian reserves capacity in which estimated by the measure of AntiMüllerian hormone (AMH) level to describe as a potential sign for ovarian reserves [14],this hormone is excreting by granulosa cells of small follicles in the ovary and its created in growing follicles till they access a step when prevalent follicle is separated from a group of antral follicles starting of puberty until menopause and regulates follicular recruitment and development within the ovary [15,16], Serum AMH level variability is very low enough through the menstrual cycle to enable measures the anti-Mullerian hormone through menstrual cycle at randomly timing [17]

\section{2-Materials and Subjects of study}

Population study enrolled in our study consisted of 50 women with primary infertility who sought medical help in private lab (Ibn Al-Nafees) in Hila city, also who attended to unit of infertility in maternity and pediatrics teaching hospital in Hila city, their aged between 20-35 years, a period work which lasted from February2015 to May 2016 year. Healthy forty parous volunteer's women who have similar age were enrolled in our study as the control group.

Five-milliliter, non-fasting venous blood of maternal and infertile women was obtained through any day within the menstrual cycle in all women without application of a tourniquet, extraordinary attention must be carried with test transport, after the specimen of blood was gathered, the concentration of ionized calcium suffer more environmental changes as a comparison with total calcium, so the sample was withdrawn anaerobically (to restrict the dioxide leakage), and analysis the blood sample which transported under cold condition was carried out within hours to reduce the lactate $[18,19]$ sera were isolated by centrifugation, sera brought together and partitioned into several aliquots and stored at -80 centigrade until required for examination, every gathered samples were performed in clusters to reduce variability within assays. Ionized calcium is obtained in $(\mathrm{mg} / \mathrm{dL})$ dependent upon the level of total calcium and albumin with the equation [20]: 
$\mathrm{iCa} \mathrm{mg} / \mathrm{dL} .=[0.9+(0.55 \times \mathrm{tCa}-0.3 \times$ albumin $\mathrm{g} / \mathrm{dL})$.

a-Determination of serum total calcium, albumin and inorganic phosphorous

Colorimetric determination of total serum calcium, serum albumin was done by using a kit supplied by (bioMeriex company) and serum Inorganic phosphorous determined by using a kit supplied by (Biolabo company), those analyses were performed according to procedures described in previous kits by using (spectrophotometer) at the biochemistry lab in college of science for women.

\section{b-Determination of serum anti-Mullerian hormone}

Anti-Mullerian hormone concentration was measured according to enzyme- linked immune sorbent assay as described in (Elabscience Biotechnology company kit), the results are determined directly by the reader of Elisa system (Bioteck company), the standard curve of anti-Mullerian determination was plotted in figure (1).

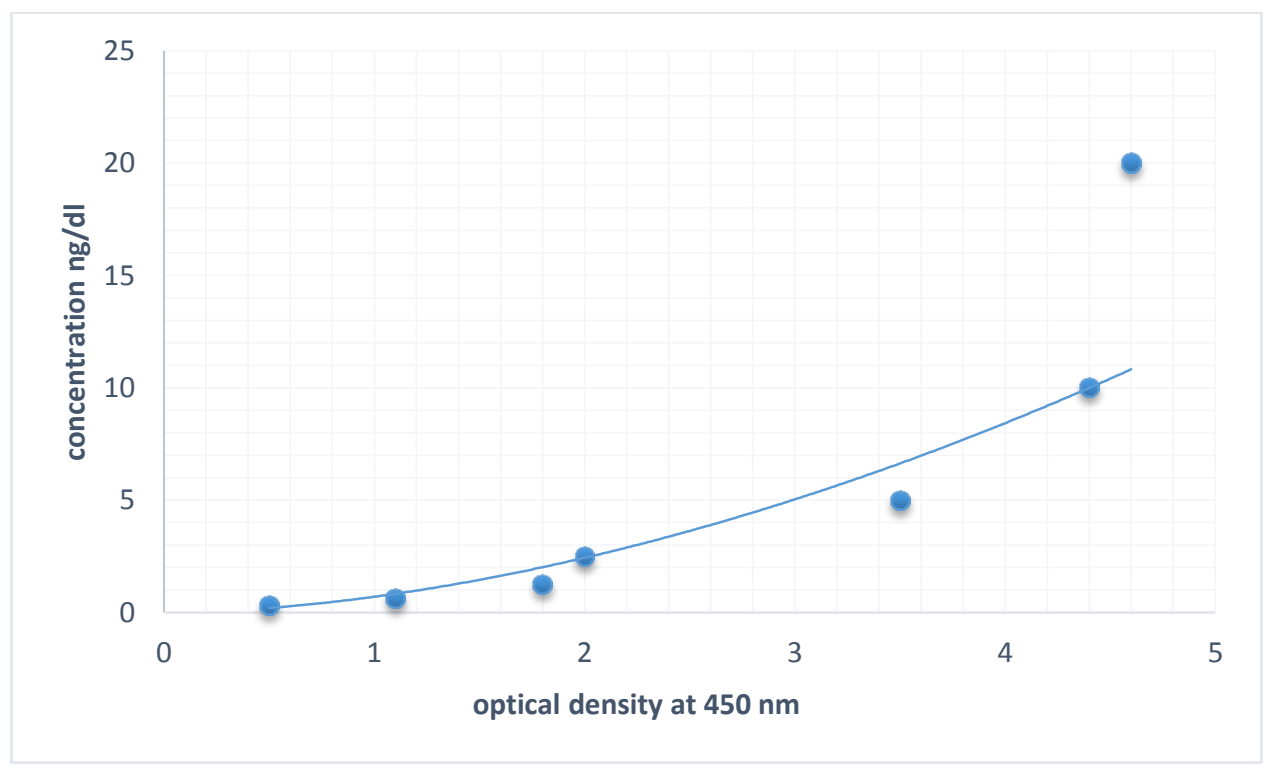

Figure (1): Standard curve of anti-Mullerian hormone (AMH)concentration

\section{C-Determination of serum parathyroid hormone}

Parathyroid hormone concentration was measured according to Elisa kit (Abnova Company) for quantitative determination of intact-PTH in human serum, results are determined directly by the reader of Elisa system (Bioteck company), the standard curve of parathyroid hormone determination was plotted in figure 2 . 


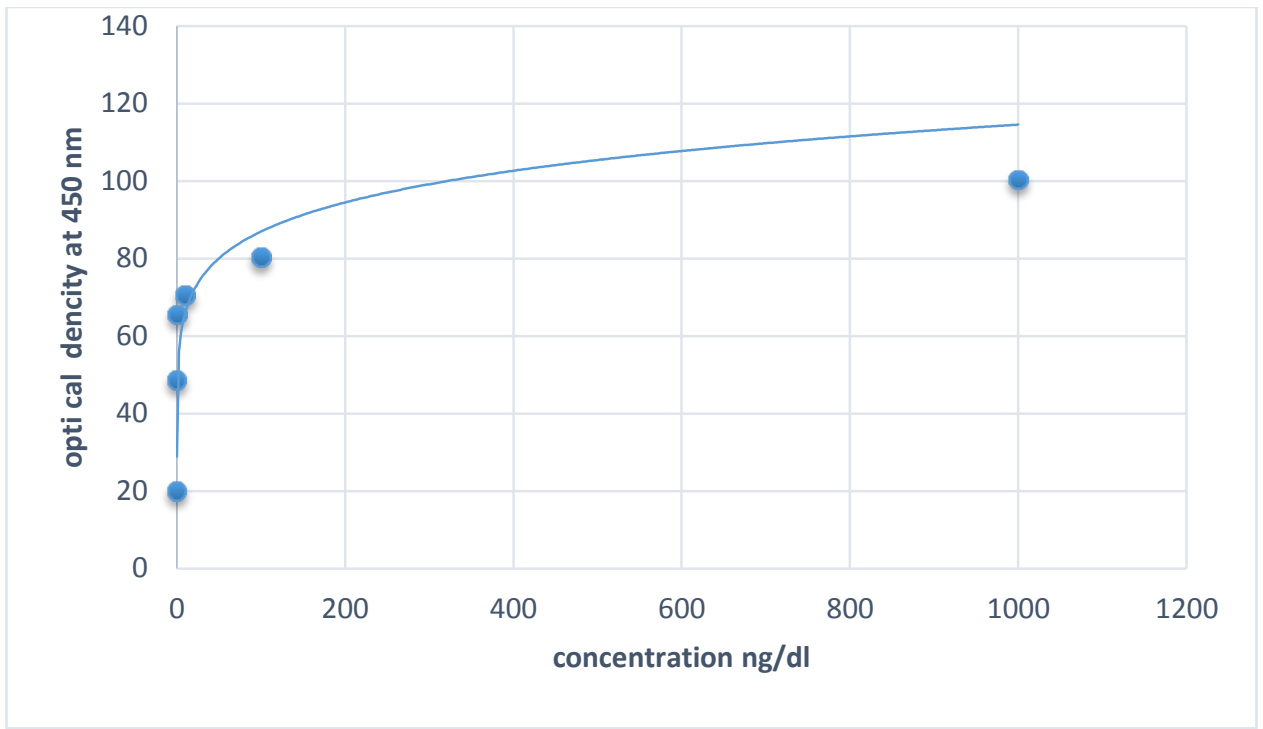

Figure (2): Standard curve of parathyroid hormone (PTH)concentration

\section{d- Statistical analysis}

The data were analyzed by (SPSS) software version 18.0 and expressed in terms as mean \pm SD. Independent Ttest analysis was used to determine any significant difference for investigating parameters between control and study group, linear regression analyses were in addition used to explore the association between ionized calcium and antiMullerian hormone level in both control and infertile groups

\section{3-Results}

The data obtained are presented in table 1. Our data shows there was no statistical difference $(p>0.05)$ between two groups for BMI, but infertile group have significantly $(\mathrm{p}<0.001)$ lower mean serum ionized calcium level than mean calcium ion value in control group, in addition those infertile women had higher significantly $(\mathrm{p}<0.05)$ albumin level compared with those in control group, moreover table 1 shows that mean serum phosphorus level which was significantly higher $(\mathrm{p}<0.01)$ in study group compared with its level in control group.

Table 1: comparison in variables between control and study groups

\begin{tabular}{|c|c|c|c|}
\hline variable & $\begin{array}{c}\text { Control group } \\
n=40 \\
\mu \pm S D\end{array}$ & $\begin{array}{c}\text { Infertile group } \\
\begin{array}{c}\mathbf{n}=\mathbf{5 0} \\
\boldsymbol{\mu} \pm \mathrm{SD}\end{array}\end{array}$ & $P$ value \\
\hline BMI $\left(\mathrm{kg} / \mathrm{m}^{2}\right)$ & $28.2 \pm 8.1$ & $28.3 \pm 8.2$ & 0.08 \\
\hline $\operatorname{Albumin}(\mathrm{g} / \mathrm{dl})$ & $3.8 \pm 0.21$ & $4.8 \pm 0.42$ & 0.0273* \\
\hline Ionized calcium (mg/dl) & $5.57 \pm 0.45$ & $4.31 \pm 0.61$ & $0.000 \times$ \\
\hline Phosphorous (mg/dl) & $3.5 \pm 0.22$ & $4.6 \pm 0.82$ & $0.0066 * *$ \\
\hline PTH (ng/dl) & $92.1 \pm 22.2$ & $94.2 \pm 32.2$ & $0.000 \times$ \\
\hline AMH (ng/dl) & $4.33 \pm 1.00$ & $2.59 \pm 1.38$ & $0.000 x$ \\
\hline
\end{tabular}

Values are mean \pm standard deviations, $* p<0.05, * * p<0.01, \times p<0.001$ 
Other than, our data revealed that infertile women had significantly $(\mathrm{p}<0.001)$ higher serum PTH value than subjects in control group, as well as, our results show that infertile women had significantly $(\mathrm{p}<0.001)$ lower concentration of serum AMH than those in control group.

In the control group, there was a significant positive correlation between ionized calcium concentration and AMH level $(\mathrm{r}=0.58, \mathrm{p}=0.000, \mathrm{n}=40)$, also there was a significant positive correlation was seen between serum ionized calcium and $\mathrm{AMH}$ level for the infertile group $(\mathrm{r}=0.70, \mathrm{p}=0.000, \mathrm{n}=50)$ as exhibited in figure ( 3 and 4$)$.

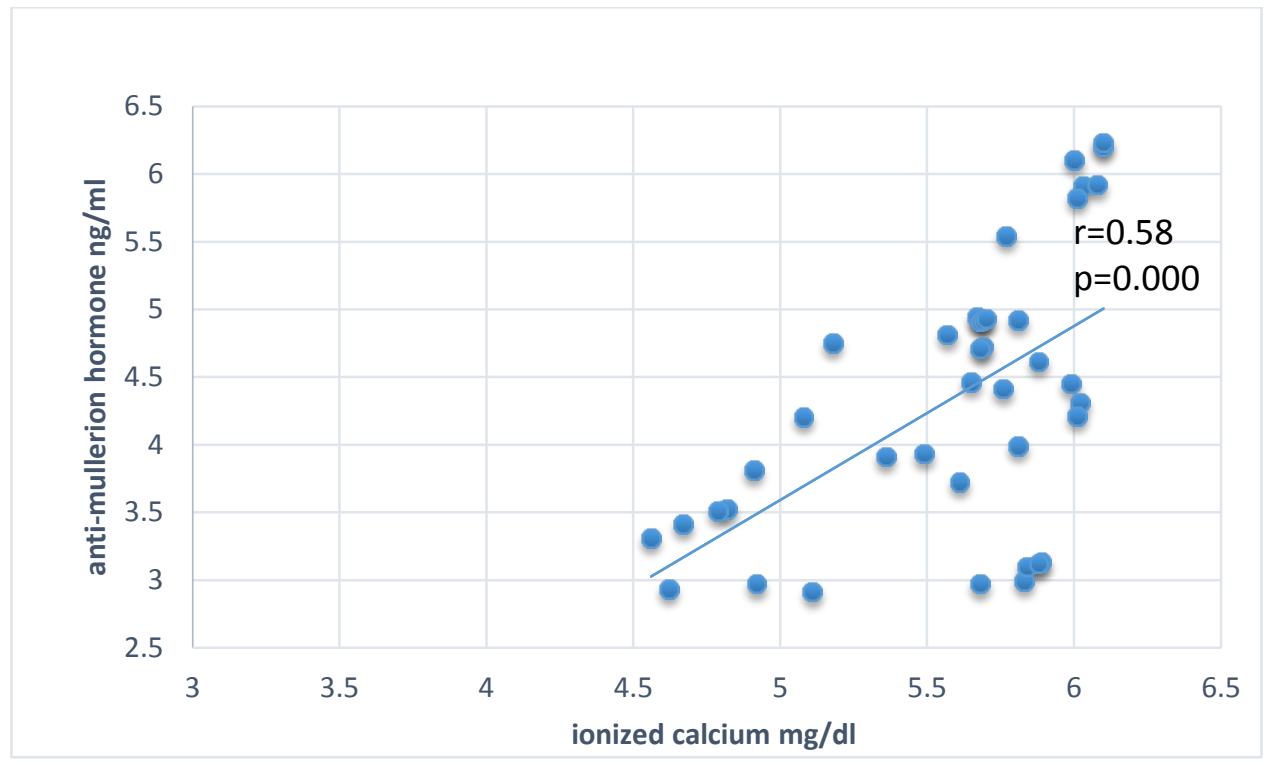

Figure (3): Correlation between ionized calcium and anti-Mullerian hormone for control women group

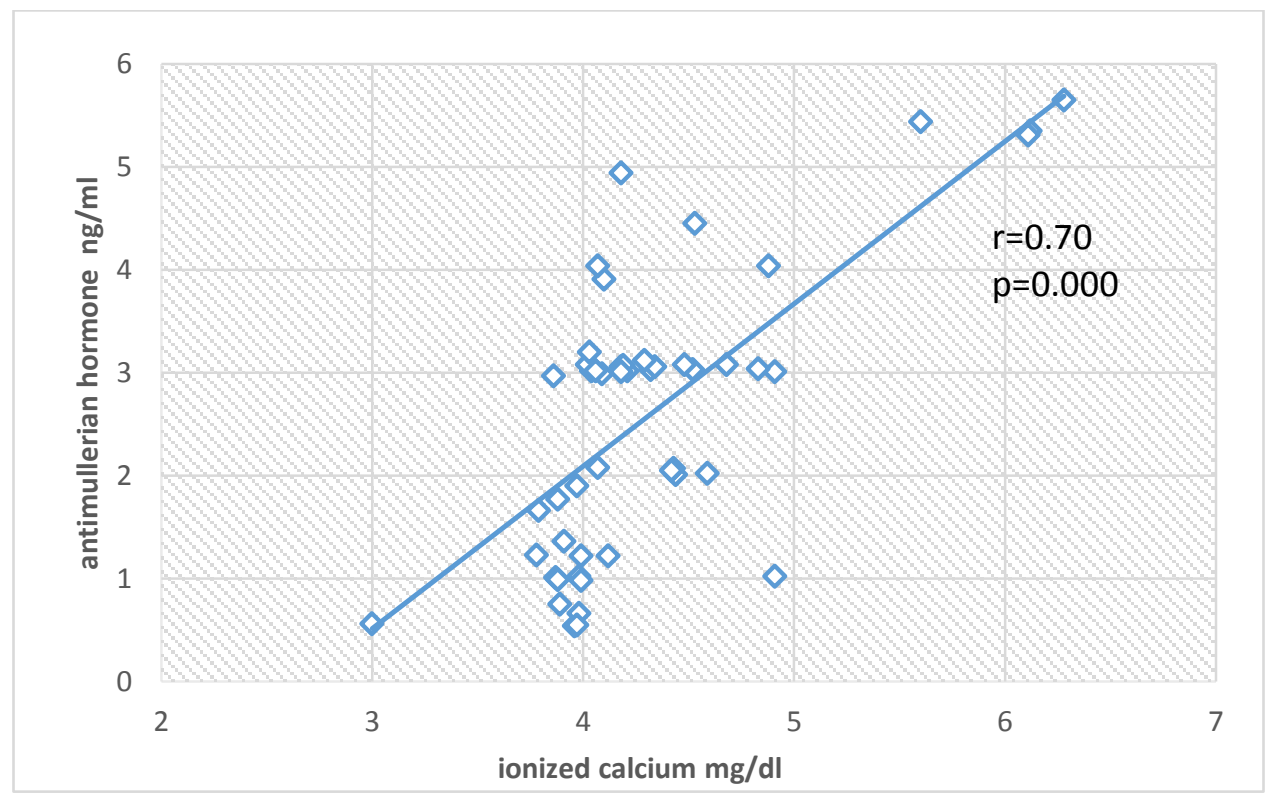

Figure (4): correlation between ionized calcium and anti-Mullerian hormone for infertile women group 


\section{4-Discussion}

In consistent with theory that suggested calcium status in body as a predictor of ovarian response to ovulation induction[21], infertile women presented a significantly diminishes in ionized $\mathrm{Ca}^{2+}$ compared with another group , that decline coincided with a progressive rise in parathyroid hormone concentration as compared with those level in women with fecundity, this results agrees with Hebert [22] who confirms that extracellular calcium ion is the most indicator of PTH secretion in response to hypocalcemia sensed by the calcium-sensing receptor, thus the production of PTH is a compensatory mechanism in order to restores effectively of calcium level and maintain normal phosphorus level, but our data showed that infertile women has significantly decreased level of calcium ion compared with control group although they have a highly significant increase in PTH concentration compared with fertile women, possibly that peripheral resistance to PTH secretion may be present and the feedback suppression of PTH that liberate by the direct impact of calcium ion not responding properly, so that increase in the PTH secretion may be persistent, progressive or transient[23] as may be occurred in the subjects of the present study. However, secretion of PTH in response to hypocalcemia that result in a lack of sunlight, diet or malabsorption is known secondary hyperthyroidism [24].

Concerning reciprocal relation among calcium ion and phosphorous which is observed clinically likely to the consequence of interrelated hormonal and physiological mechanism and interact in several fundamental processes [25] as similar obtain in control subjects but the data about infertile women is different, one explanation for this result may that raise in serum inorganic phosphorous as large as does not make a decline in serum ionized calcium by means of immediate physicochemical calcium hydrogen phosphate (CaHPO4 )complex build great sufficient that is the reason to create secondary hyperparathyroidism $[25,26]$. Inclusively, a previous study has shown that reduced serum calcium and elevated phosphate levels are accompanying with an elevation of parathyroid hormone level [27], the same responses may have existed in the current study among the infertile population, other project mentioned that disturbance in relation between calcium and phosphorous owing to binding some kinds food with phosphorous which would have an impact on the net amount of phosphorous absorbed and concentration of extracellular phosphorous[28] in view of the fact hydrogen ions compete with calcium for binding site on albumin and other proteins hence calcium ion is affected by $\mathrm{pH}$ of women specimen [29] this gives suggestion that diminishing concentration of calcium ion among infertile group may refer to their alkaline environmental specimen, likewise availability some binding agents for example: cellulose, phosphate, and oxalate lower the absorption of calcium by decrease of bioavailability dietary calcium [26].

In concerning with serum ionized calcium concentration pertain to fertility status, it is important to point out the level of intracellular calcium lower than the extracellular because of relative membrane impermeability and membrane pumps employing active transport, this give suppose that decrease entry of calcium ion into inner cells in consequence to decline concentration of calcium ion out of the cell [30] whereas that changes in the intracellular free calcium serve as signals that occur for oocyte and egg and embryos activation [31]. By using points proposed in the previous literature the calcium considered a signal in mammals eggs fertilization and involving early in oocyte maturation to electrical modification in gametes due currents calcium ion through the oocyte plasma membrane across ion channels which demonstrated on it [32] within this context, the release of unfertilized eggs which is motivating by intracellular $\mathrm{Ca}^{+2}$ for triggering the embryonic development is mediated sometime by a synergic cooperation by both intracellular and extracellular calcium ions which plasma membrane currents [33] from this sought the rate of calcium provided maternal decidua aids in the fertilization of the egg and implantation of the blastocyst during pregnancy hence calcium deficiency during trimesters of pregnancy causes many disorders[34,35]

With regard to the role of calcium ion in follicular growth, previous studies were have found that activation and maturation of animal oocyte is mediated by calcium ion resulting in the resumption and progression of follicular development to form the haploid gametes to fertilization at the first meiotic prophase [36] this raises the possibility in our study that calcium status in the body as a predictor of ovarian response to ovulation induction[21] Our findings included correlation of high calcium content with ovarian maturation [37], decreased ionized calcium level accompanied by the low concentration of AMH was showed among infertile women and the opposite is true in the fertile women, this may has corresponded with previous studies in which recorded that vitamin D has potential role in AMH expression, similarly other medical research sign to the role of vitamin D in regulating calcium uptake and stimulating differential cell $[38,39]$.

Accordingly, this agrees with our results which demonstrated a positive linear relationship between calcium ion and AMH levels in both fecund and not fecund subjects ,however this consistent with one researcher who confirm that calcium ion may regulate $\mathrm{AMH}$, then the magnitude of women's calcium ion should correlate with the hers magnitude of $\mathrm{AMH}$ and the low level of $\mathrm{AMH}$ indicator to the diminishing ovarian reserve $[40,41]$ the suitable elucidation to the 
same result was founded in the current study suggested that AMH concentration mirror to the number of follicles / follicular cells that produce AMH[42].

Own obtains have been suggested that the level of calcium ion act as an enhancer drive the follicles cells production then consequently contribute in stimulation of anti-Mullerian hormone secretion.

\section{5- Conclusion}

Our conclusion suggested that serum ionized calcium is a predictive of baseline ovarian reserve, which may in turn sign the level of anti-Mullerian hormone and any disturbance in calcium homeostasis may have been altered the ovarian reserve and result in reduction of reproductive capacity.

\section{CONFLICT OF INTERESTS}

There are no conflicts of interest.

\section{6- Reference}

[1] Johnson, Laura E., and Hector F. DeLuca. "Vitamin D receptor null mutant mice fed high levels of calcium are fertile." The Journal of nutrition 131, no. 6: 1787-1791. 2001.

[2] Sun, Weiwei, Hui Xie, Ji Ji, Xiaojie Zhou, David Goltzman, and Dengshun Miao. "Defective female reproductive function in 1, $25(\mathrm{OH})$ 2D-deficient mice results from indirect effect mediated by extracellular calcium and/or phosphorus." American Journal of Physiology-Endocrinology and Metabolism 299, no. 6: E928-E935. 2010.

[3] Carafoli, Ernesto. "Calcium signaling: a tale for all seasons." Proceedings of the National Academy of Sciences 99 , no. 3: 1115-1122.2002.

[4] Barrige, M. J., M. D. Bootman, and H. L. Roderick. "Calcium signaling: dynamics, homeostasis, and remodeling." Nature 4: 517-529.2003

[5] Burnett, Robert W., Torben F. Christiansen, Arthur K. Covington, Niels Fogh-Andersen, Wolf R. Külpmann, Andrzej Lewenstam, Anton HJ Maas et al. "IFCC recommended reference method for the determination of the substance concentration of ionized calcium in undiluted serum, plasma or whole blood." Clinical chemistry and laboratory medicine 38, no. 12: 1301-1314. 2002.

[6] Heaney, Robert P. "Long-latency deficiency disease: insights from calcium and vitamin D." The American journal of clinical nutrition 78, no. 5: 912-919. 2003.

[7] MENG, Hui-ping, Dong-Li LI, and Yan-Ze YANG. "Calcium and human health." Studies of Trace Elements and Health 5: 034.2010.

[8] Moody, William J. "5 The Development of Voltage-Gated Ion Channels and Its Relation to Activity-Dependent Developmental Events." In Current topics in developmental biology, vol. 39, pp. 159-185. Academic Press, 1998.

[9] Tosti, Elisabetta, and Raffaele Boni. "Electrical events during gamete maturation and fertilization in animals and humans." Human Reproduction Update 10, no. 1: 53-65.2004.

[10] Clark VL, Kruse JA. "Clinical methods: the history, physical, and laboratory examinations". Jama ;264(21):28089.2014 .

[11] Spina, Annamaria, Luca Sorvillo, Antonietta Esposito, Alessia Borgia, Luigi Sapio, and Silvio Naviglio. "Inorganic phosphate as a signaling molecule: a potential strategy in osteosarcoma treatment." Current pharmaceutical design 19, no. 30: 5394-5403.2013.

[12] Wulaningsih, W., M. Van Hemelrijck, Karl Michaelsson, N. Kanarek, W. G. Nelson, J. H. Ix, E. A. Platz, and S. Rohrmann. "Association of serum inorganic phosphate with sex steroid hormones and vitamin D in a nationally representative sample of men." Andrology 2, no. 6: 967-976. 2014

[13] Vaidya, Anand, Gary C. Curhan, Julie M. Paik, Molin Wang, and Eric N. Taylor. "Physical activity and the risk of primary hyperparathyroidism." The Journal of Clinical Endocrinology \& Metabolism 101, no. 4 :1590-1597.2016. 
[14] Verma, Anil Kumar, Sarita Rajbhar, Jyoti Mishra, Mayank Gupta, Mratunjai Sharma, Geeta Deshmukh, and Wahid Ali. "Anti-Mullerian hormone: a marker of ovarian reserve and its association with polycystic ovarian syndrome." Journal of clinical and diagnostic research: JCDR 10, no. 12: QC10. 2016.

[15] Themmen, Axel PN. "Anti-Müllerian hormone: its role in follicular growth initiation and survival and as an ovarian reserve marker." JNCI Monographs 2005, no. 34: 18-21.2005.

[16] Zec, Ivana, Dubravka Tislaric-Medenjak, Zeljka Bukovec Megla, and Ivana Kucak. "Anti-Mullerian hormone: a unique biochemical marker of gonadal development and fertility in humans." Biochemicals medical: 21, no. 3: 219230.2011 .

[17] Anderson, Richard A. "What does anti- Mullerian hormone tell you about ovarian function?" Clinical endocrinology 77, no. 5: 652-655.2012.

[18] Wybenga, Donald R., F. A. Ibbott, and Donald C. Cannon. "Determination of ionized calcium in serum that has been exposed to air." Clinical chemistry 22, no. 7 :1009-1011. 1976.

[19] Căpriță, Rodica, Adrian Caprita, and Iuliana Cretescu. "Estimation of ionized calcium and corrected total calcium concentration based on serum albumin level." Scientific Papers Animal Science and Biotechnologies 46, no. 1 :180184.1913.

[20] Jafri, Lena, Aysha Habib Khan, and Saba Azeem. "Ionized calcium measurement in serum and plasma by ion selective electrodes: comparison of measured and calculated parameters." Indian Journal of Clinical Biochemistry 29 , no. 3 (2014): 327-332.

[21] Chang, Eun Mi, You Shin Kim, Hyung Jae Won, Tae Ki Yoon, and Woo Sik Lee. "Association between sex steroids, ovarian reserve, and vitamin D levels in healthy nonobese women." The Journal of Clinical Endocrinology \& Metabolism 99, no. 7 :2526-2532. 2014.

[22] Hebert, Steven C. "Extracellular calcium-sensing receptor: implications for calcium and magnesium handling in the kidney." Kidney international 50, no. 6 (1996): 2129-2139.

[23] Higgins JPT and Green S (editors). Cochrane Handbookfor Systematic Reviews of Interventions Version 5.1.0 [updated March 2011]. The Cochrane Collaboration ...

[24] Wysolmerski JJ, Insogna KL. "The parathyroid glands, hypercalcemia, and hypocalcemia". InGoldman's Cecil Medicine (Twenty Fourth Edition), pp: 1591-1601.2011.

[25] Adler, Andrew J., Nereida Ferran, and Geoffrey M. Berlyne. "Effect of inorganic phosphate on serum ionized calcium concentration in vitro: A reassessment of the "trade-off hypothesis"." Kidney international 28, no. 6 :932935.1985

[26] Peacock, Munro. "Calcium metabolism in health and disease." Clinical Journal of the American Society of Nephrology 5, no. Supplement 1: S23-S30. 2010.

[27] Bringhurst FR, Demay MB and Kronenberg HM. "Hormones and disorders of mineral metabolism".In :Melmed S,Polousky KS,Larsen PR,Kronenberg.HM,eds.Williams Textbook of Endocrinology. $13^{\text {th }}$ ed.Philadelphia,pa:Elsevier Saunders,chap28.2011.

[28] Friedlander, Gérard. "Regulation of renal phosphate handling: recent findings." Current opinion in nephrology and hypertension 5, no. 4 :316-320. 1996.

[29] Wang, Sihe, Elizabeth H. McDonnell, Frank A. Sedor, and John G. Toffaletti. "pH effects on measurements of ionized calcium and ionized magnesium in blood." Archives of pathology \& laboratory medicine 126, no. 8 :947950.2002 .

[30] Guyton, A. C., and J. E. Hall. "Parathyroid hormone, calcitonin, calcium and phosphate metabolism, vitamin D, bone and teeth." Textbook of medical physiology,9:985-1002.1996.

[31] Rattray, Lillie Frank. "Problems of Fertilization." (1919).

[23] Tosti, Elisabetta, and Raffaele Boni. "Electrical events during gamete maturation and fertilization in animals and humans." Human Reproduction Update 10, no. 1 :53-65.2004. 
اظهرت نتائج معامل الارتباط وجود علاقة ارتباطية معنوية بين تركيز الكالسيوم المتاين ومستوى هرمون مضاد موليرين في كلا مجموعتي الدراسة

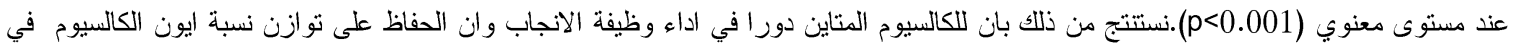
الجسم له دور في تعزيز محتوى المبيض من البيوض وان ابي تغيير في استتباب الكالسيوم يمكن ان يؤدي الى تقليل المخزون من البيوض في المبيض وبالتالي تقليل افراز هرمون مضاد مو لارين. الكلمات الدالة:استتباب الكالسيوم المتاين, عقم النساء, هرمون مضاد موليرين. 